\title{
Gadget use and visual acuity among school-age children in Tagbilaran city central elementary school: A correlational study
}

\author{
Jdidah Mae Sealza1, Ma. Zena Gulta Amora², Anabella A. Salise-Oncog ${ }^{3 *}$ \\ 1 lloilo Street, Aluba Subd. Phase 2, Macasandig, Cagayan de Oro City 9000 \\ 2 Profession: Doctor of Optometry, Field of Specialty: Optometrist, Address: Poblacion, Anda, Bohol \\ 3 Department of Pediatric Medicine, Gov. Celestino Gallares Memorial Hospital \\ *Corresponding Author: Dr. Anabella A. Salise-Oncog, Department of Pediatric Medicine, Gov. Celestino Gallares Memorial \\ Hospital, Tagbilaran, Philippines \\ Email: abelle salise@yahoo.com; Tel: (38) 9173042453
}

Received: February 19, 2021; Accepted: March 11, 2021

\begin{abstract}
Objective: To determine the correlation between gadget use and visual acuity in school-age children. Methodology: This is a cross-sectional survey on 120 school-age children in Tagbilaran City Central Elementary School conducted from July 1, 2019 to August 31, 2019. A questionnaire was used to ask information regarding access to gadget and duration of gadget use. A visual acuity examination using the Snellen eye chart was performed by an optometrician. The results of the visual acuity examination were noted alongside the duration of gadget use. Results: Majority of the pupils use a gadget for 1 to 1.5 hours in a day; but $11.7 \%$ use a gadget longer than 4 hours. Majority of the pupils have emmetropia, $7.5 \%$ have myopia, and none have hyperopia. Correlation studies show that there is no association between duration of gadget use and visual acuity of school-age children ( $p=0.589,|r|=0.050$ ). Conclusion: There is no correlation between gadget use and visual acuity of school-age children. The duration of gadget use has no impact on the development of visual defects in school-age children.
\end{abstract}

Keywords: Gadget, Visual acuity, School-age children.

\section{INTRODUCTION}

Healthy eyesight is unarguably valuable. Out of all the five sense organs, the sense of sight is considered to be the most important in humans; and this is reflected in how complicated human eyes are relative to other creatures. Many animals gain most of the information about their environment through their sense of smell, but humans do by seeing the world in its vivid colors.

The function of the eyes in general is the end result of the coming together of the functions of each individual component of the eye as an organ: from the external parts like the eyelashes and the conjunctivae, to the extraocular muscles, down to the innermost parts like the photoreceptor cells in the retina. Each individual part works separately from, yet harmoniously with the other parts of the eye and the visual system to produce a sensory experience, that is the sight, and its subsequent vision.

Sight and vision are two different entities. Sight is physical. It is the sensory experience in which light reflects off shapes and objects and the eyes then focus this light. Signals are sent to the brain to be converted into images. Vision, on the other hand, is a thought process, or a metaphysical concept ${ }^{[1]}$. Vision produces an understanding of what is seen, where it is, and how to react to it by combining information from many sensory systems to create a perception of reality. It is a dynamic and interactive process developed through experience to gain understanding of the external visual space world ${ }^{[2]}$.

Sight and vision are harmonious and are very important in our lives. They help to connect people with their surroundings and bring beauty and understanding of the world to us. They also keep us safe by providing awareness of the dangers around us. And in turn, they keep our minds sharp and alert. Frequent stimulation of the mind and philosophical interpretation of one's sense of vision helps with overall health and intelligence [1]. Thus, learning, especially in children, relies on vision ${ }^{[3]}$.

With these functions of sight and vision in mind, one should realize the importance of maintaining a healthy eyesight. Unfortunately, statistics from the World Health Organization 
showed that there are 1.3 billion people globally who have some form of vision impairment and that in $80 \%$ of them, the vision impairment is considered avoidable. The leading causes of vision impairment worldwide are uncorrected refractive errors and cataracts ${ }^{[4]}$.

Refractive error, or ametropia, is an error in focusing of light by the eye from an object onto the retinal plane ${ }^{[5]}$. Refractive error consists of myopia, hyperopia, and astigmatism [6], and is corrected mainly with spectacles. Myopia or nearsightedness is a refractive error where light focuses in front of, instead of on the retina [7]. This may be caused by excessive refractive power and/or axial lengthening of the eye that results in anterior displacement of focus from the retina [8]. In myopia, distant objects are blurry while close objects appear normal. Hyperopia is the condition where light is focused behind, instead of on the retina. It is often caused by an eyeball that is too short, or misshapen lens or cornea. This results in close objects being blurry, and distant objects appearing normal ${ }^{[9]}$. Astigmatism is the refractive error that results from imperfections in the curvature of the cornea (corneal astimagtism) or the lens (lenticular astigmatism). And since its pathology is not that of the axial length of the eyeball, it can co-exist with either myopia or hyperopia. In astigmatism, vision for both near and distant objects is blurry or distorted ${ }^{[10]}$.

Uncorrected refractive errors are a major disease burden among children around the world [11-22]. In the Philippines, it has been reported that 1 in 4 (24.53\%) first grade students has errors of refraction, with astigmatism (22.64\%) being the most common, followed by myopia (3.77\%), and hyperopia (2.83\%) ${ }^{[23]}$. This is worse than the statistics previously reported by the Department of Health which stated that $10 \%$ of grade school children have eye problems, many of which were undetected. A quarter of these children had amblyopia and the rest had main error of refraction ${ }^{24]}$.

More important than the number of children having error of refraction is that the consequences of uncorrected refractive errors are even heavier: educational loss, low productivity, and impaired quality of life [25-27]. Refractive errors can affect children's routine schoolwork and daily activities as these children have difficulty concentrating on curricular activities [28, 29]. The worst outcome of uncorrected refractive error is blindness and its manifold consequences [30]. Hence, uncorrected refractive errors can pose problems not only to the child and to his parents and family, but to the government as well [24].

Several factors have been reported to cause refractive errors in children. Age has been seen to affect development of refractive errors, particularly of myopia ${ }^{[31]}$. Gender, on the other hand, has not been consistently shown to affect development of refractive errors. Researchers from Sydney, Australia found that girls engaged in more myopigenic activity than boys [32]; however, a study from Taiwan stated that although more girls had myopia, gender did not cause statistical differences [33].

Familial factors were also seen to contribute to development of refractive errors. The study conducted by Peng in Taiwan showed that there was a higher rate of myopia in children of myopic parents [33]. However, parental history of myopia was seen to significantly affect only children $5-6$ years old, and not children $12-17$ years ${ }^{[34]}$. Ethnicity was also reported to affect the development of refractive errors. Asian origin was seen to be associated with higher rate of myopia [32, 35]. Even parental behavior guidance and the environment where children grow up were also reported to affect the development of refractive errors.
This was depicted in a Singaporean study that reported the contribution of familial siblings to the changes in refractive errors and vitreous chamber depths ${ }^{[36]}$.

Educational factors have also been associated with refractive errors. A significantly strong correlation between educational attainment and refractive errors has been reported by British researchers. In their study, Williams and Hammond noted that $16 \%$ of primary school graduates had myopia, and $35 \%$ of people with a higher education degree were diagnosed with myopia [37]. In a large-scale survey in Greater Beijing area, it was noted that school types and reading in dim light, as well as daily long-hour and continuous study without rest over a long period of time are correlated with myopia [31]. This has the implication of the school being one of the most important establishments to lead in the prevention particularly of myopia ${ }^{[38]}$.

Another important factor is the eye-to-object distance. Nearwork tasks are particularly dangerous to vision [39, 40]. A strong correlation between the occurrence of myopia and the time children spent on near-work tasks was found in an investigation of 1,108 kindergarten children ages $5-7$ in Taiwan ${ }^{33}$. Near-work activities include reading/studying, computer use, playing Game Boy, watching television, and playing electronic gadgets; all of these increase eye-use time [33,41,42]. Other researchers have found a correlation between decreasing hours of outdoor activities and incidence of myopia [43, 44].

Technology undeniably plays a vital role in our daily lives. This includes electronic games, home computers, handheld devices, and other type of gadgets like the television and radio. Children use gadgets for various purposes like playing games, watching videos, listening songs, chatting with their friends, and browsing different websites. Unfortunately, gadgets are popular in children as likely in elders ${ }^{[45]}$.

Nowadays, it is no longer surprising to see a 2-year old baby who can and knows how to use a gadget ${ }^{[45]}$. Parents are partly to blame for this phenomenon. There is an apparent increased dependence of parents on gadgets for parenting. If the baby is not taking feed, parents show nursery rhyme over the smartphone or tablet to distract the baby. When the baby cries, parents introduce gizmos that play "shush" sound to comfort and console the baby. If the baby is not sleeping, parents get baby sleep monitor that plays sounds to help baby sleep ${ }^{[46]}$. And this is just the start. When kids grow older, they want a mobile phone or a video game because their best friends have one. Eventually, they shift from physical plays to digital games where they enjoy competing with each other online. And the addictive way social media platforms are engineered kept these children obsessed with what others have to say about them. So that what started as a convenient way of distraction became an addiction ${ }^{[47]}$.

The Centers for Disease Control and Prevention (CDC) has reported that children ages 8 - 10 spend about 6 hours in front of a screen using entertainment media, nearly 4 hours of these in front of the television. Children $11-14$ years spend 9 hours for screen time, 5 of these watching television. Children $15-18$ years spend 7.5 hours in front of a screen, 4.5 of these in front of the television [48]. This is sad because these hours could have been spent on a game of basketball, or walking the dog, or other physical activities.

The deleterious effect of gadget use on a child's vision has been reported in all forms of media and across different countries. Dr. Muthukrishnan, a Malaysian ophthalmologist, believes that one of the contributing factors to the rise in children wearing glasses is the usage of electronic gadgets. He said that long hours of 
exposure to electronic gadgets could cause refractive errors such as long-sightedness, short-sightedness or astigmatism in children ${ }^{[49]}$. Ophthalmologists in the United Arab Emirates also say the same thing - excessive screen time strains children's eyes. Dr. Naqi, the head of the ophthalmology department at Dubai Hospital, stated that there is a notable higher incidence of myopia, and that it is starting at a younger age compared to the pre-screen/tablets era. This was confirmed by Dr. Thakur, an ophthalmologist from Mediclinic Welfare Hospital, who added that aside from the increase in the number of cases of refractive errors, there is also a faster progression or worsening of preexisting short-sightedness. Dr. Thakur also said that children's risk of getting myopia fell by $2 \%$ for every extra hour they spent outdoors a week, and that fewer children became short-sighted when they were made to spend 80 minutes of recess time outdoors every day compared to those who were not required to do that ${ }^{[50]}$. The Deccan Chronicle in India reported that vision impairment due to refractive errors has become a modern lifestyle disorder among children and youngsters, just like hypertension, cholesterol and diabetes, and are mainly caused by continuous use of mobile phone, television and computer [51]. Our very own Department of Health also reported that there is a rise in visual impairment among school-age children due to the use of gadgets like mobile phones and tablets ${ }^{[52]}$.

Children who spend multiple hours staring at digital devices are at risk of developing these vision-related problems: computer vision syndrome, unhealthy posture, nearsightedness, and increased exposure to blue light ${ }^{[53]}$. Computer vision syndrome (CVS), also known as digital eye strain (DES) has been estimated to have developed in approximately 60 million people ${ }^{54}$. CVS represents a group of visual and extraocular symptoms associated with the sustained use of visual display terminals (VDT). This syndrome include visual symptoms, ocular symptoms, asthenopia or eye strain, light sensitivity, musculoskeletal and general symptoms [55]. The visual symptoms are related to blurred vision: constant blurred vision, post work distance blur, and intermittent blurred vision at near. Ocular surface-related symptoms are itching eyes, burning eyes, foreign body sensation, and sore eyes. Patients who work in front of a VDT for more than 4 hours a day can develop dry eye disease. Dry eyes in CVS has often been associated with lesser frequency of blinking when people use electronic screens. A person blinks an average of 15 times per minute. This can drop to 5 times per minute due to the high attention required while using an electronic screen. Since blinking is a natural mechanism that keeps the eyes moist, lubricated and clean, a lower blink rate therefore causes dry eyes and irritation. Desktop computers and wall-mounted televisions can worsen the condition because one has to look upwards, making the eyes open wider and exposing more surface area of the eye to evaporation ${ }^{[56]}$. Ocular complaints can also be related with the dysfunction of Meibomian glands ${ }^{[57]}$. Some patients complain of excessive tears and excessive blinking [58]. The prevalence of asthenopia among gadget users is estimated between $55 \%$ and $81 \%$. Eye strain from prolonged use of gadgets can cause removal of the near point of convergence, deviation of phoria for near vision and inaccurate accommodative response [54]. However, these modifications are only temporary and do not have a permanent effect on accommodation [59]. Musculoskeletal symptoms may include neck pain, back pain, and shoulder pain ${ }^{[55]}$. General symptoms in CVS are not directly linked with eyes and occur towards the end of the day like irritability, increased nervousness, general fatigue and drowsiness. CVS is temporary and is heightened by inadequate lighting condition [58]. CVS is still underdiagnosed and people should be made aware of the bad effects the prolonged use of gadgets has on eyesight ${ }^{660]}$.
It is common to slouch inward, round the back and shoulders, and tilt the head back and jut the chin forward when one uses a computer or digital device for prolonged periods. This unnatural posture called "turtling" leads to many of the non-visual symptoms of computer vision syndrome ${ }^{[53]}$.

Nearsightedness or myopia prevalence has been seen to have significantly increased in the last few decades and this trend coincides with the increased use of computers and digital devices by children [53]. In a study conducted in school children in Salem, Tamil Nadu, it was found out that out of students with more gadget usage, $75 \%$ were myopic; out of students who watch television at close distance, $85 \%$ were myopic. Both findings indicate that visual gadgets and habit of using them are major factors associated with myopia [61].

Blue light is a high-energy visible light emitted by the LED screens of computers, tablets, smartphones and other digital devices ${ }^{[53]}$. Blue light is that light with wavelengths in the 500 $\mathrm{nm}$ to $381 \mathrm{~nm}$ range [62]. A study on blue light exposure conducted on rhesus monkeys showed retinal degeneration that developed after exposing the monkeys to high-intensity blue light at $441 \mathrm{~nm}$ for a duration of 1000 seconds [63]. Follow up animal studies sought to explore the basis to explain why blue light reactions cause retinal degeneration. Pautler, Morita and Beenley found in their study on bovine retinal tissues that cytochrome oxidase is the key enzyme in the respiration of the retina in higher mammal and blue light exposure destroyed cytochrome oxidase and inhibited cellular respiration [64]. Acting on this discovery, Chen conducted a similar study on rats and had similar results, leading him to conclude that inhibition of cytochrome oxidase by blue light exposure and the consequent suppression of the cellular metabolism is a potential cause of retinal degeneration [65]. Furthermore, blue light emitted by sharp displays prevents the release of melatonin, an important sleep inducing hormone ${ }^{[47]}$. Thus, blue light not only can cause retinal degeneration, but also can cause sleep impairment in children [47].

The gadget 'epidemic' has not spared the Boholano children. This prompted the authors to conduct a study on the effects of gadget use on the visual acuity in Boholano kids.

\section{SIGNIFICANCE OF THE STUDY}

The authors believe that this study will benefit the following stakeholders:

\section{Department of Health}

This study would contribute to the achievement of the goal of the National Prevention of Blindness Program of the Department of Health which is to reduce the prevalence of avoidable blindness in the Philippines through the provision of quality eye care [66]. This study would specifically answer the second objective of this program which is to reduce visual impairment due to refractive errors by $10 \%$. This study can also help to achieve the third objective of the program which is to reduce the prevalence of visual disability in children from $0.3 \%$ to $0.2 \%$.

This study would also add information or data that may help in the revision or promulgation of programs that aim for healthy eyesight for Filipinos.

\section{Department of Education}

The schools are important partners in the prevention of disease 
and maintainance of good overall health and well-being. The results of this study can be shared with the school-site of this study and can be the basis for programs that will alleviate, if not totally eliminate, vision problems.

\section{Gov. Celestino Gallares Memorial Hospital}

This study is a manifestation of the institution's vision of becoming a premier research facility.

\section{Department of Pediatrics}

This study would strengthen the commitment of the department to help the community by any way it can. This can provide data that will serve as basis in the design of programs on healthy eyesight applicable in our own outpatient department and in our chosen community. These programs may include departmentinitiated vision screening, or health-teaching activities around healthy eyesight.

This can also provide a springboard for researches on related topic.

\section{Boholano Children}

The ultimate beneficiaries of this study would be the Boholano children. The results of this study can help produce relevant laws and programs to support and maintain healthy eyesight particularly in children. Furthermore, this study would not only identify children who need correction of errors of refraction but would also help in the prevention of visual impairment by promoting awareness of the negative effects of gadget use on children's eyes.

\section{OBJECTIVES OF THE STUDY}

General objective: To determine the correlation between gadget use and visual acuity in school-age children

\section{Specific objectives:}

1. To determine the duration of gadget use by school-age children:
a. $\leq 30$ minutes
b. $31-\leq 60$ minutes
c. $61-\leq 90$ minutes
d. $91-\leq 120$ minutes
e. $121-\leq 150$ minutes
f. $151-\leq 180$ minutes
g. $181-\leq 210$ minutes
h. $211-\leq 240$ minutes
i. $>240$ minutes

2. To measure the visual acuity of school-age children who use gadgets

3. To categorize the visual acuity of school-age children who use gadgets:
a. Emmetropia
b. Myopia
c. Hyperopia

4. To determine the correlation of visual acuity of school-age children with the duration of gadget use

\section{METHODOLOGY}

Research Design: This is a cross-sectional survey study.

Study Population and Locale: This study included 120 schoolage children enrolled in Tagbilaran City Central Elementary School. The sample size was computed using Cochran's Sample Size Formula based on a 95\% confidence level and a margin of error of about $9 \%$. The formula is as follows:

$$
\mathrm{n}_{0}=\frac{\mathrm{z}^{2} \mathrm{pq}}{\mathrm{e}^{2}}
$$

Where:

$\mathrm{n}_{0}=$ sample size

$z=$ selected critical value of desired confidence level

$p=$ estimated proportion of an attribute that is present in the population

$q=1-p$

$\mathrm{e}=$ desired level of precision

\section{Inclusion and Exclusion Criteria:}

\section{Inclusion criteria:}

1. Children $6-12$ years old

2. Formally enrolled in the mainstream classes at Tagbilaran City Central Elementary School

3. Able to identify letters

\section{Exclusion criteria:}

1. Children wearing corrective eyeglasses

2. Children who do not own a gadget or have no access to gadget

Sampling Technique: This study utilized simple random sampling.

1. The complete list of pupils aged between 6 to 12 years and enrolled in the current school year was obtained from the office of the principal and served as the sampling frame.

2. The names in the sampling frame were numbered from 1 to $\mathrm{N}$ (or the number assigned to the last student in the list) such that each student got a unique number.

3. The author utilized the Excel computer program to produce a list of numbers and their corresponding names in the sampling frame. These pupils were included in the study.

Duration of the Study: The study ran from July 1, 2019 to August 31, 2019.

Research Instrument: A questionnaire was used to ask information regarding access to gadget and duration of gadget use.

\section{Data gathering:}

1. An approval of the research proposal by the hospital Institutional Review Board was sought.

2. A letter was written to the school principal to ask permission to conduct the study in their school. A meeting with the school staff was held to explain the procedures of the study. 
3. The sampling process was started as soon as the necessary permissions were obtained.

4. An informed consent was obtained from the parents/guardian of the chosen pupil. An informed assent was also obtained from the chosen pupil.

5. When an informed consent was given, the chosen pupil was interviewed by the principal investigator regarding access to gadget and the duration of gadget use.

6. A pilot test was performed before the conduct of the research proper.

7. After the interview, the chosen pupil was examined by the co-author optometrician using the Snellen eye chart.

a. The screening was performed in a quiet room with adequate lighting and ventilation.

b. The subject was asked to stand at a distance of 20 feet from the Snellen eye chart.

c. The eyes were tested separately. One eye was occluded while the other eye was tested.

d. The subject was asked to read the letters in the Snellen eye chart from the line with the biggest letters down to the line with the smallest letters legible for the subject.

8. The visual acuity results were categorized into emmetropia, myopia, or hyperopia.

9. Parents of pupils with refractive errors were advised about the condition of their children's eyes and about the need for further tests to rule out astigmatism. They were also advised of the need for corrective eyeglasses to correct the refractive errors in their children.

10. All results of the visual acuity test were tabulated alongside the duration of gadget use.

\section{Statistical Analysis:}

Descriptive statistics were generated for all variables. Frequencies and percentages were generated for categorical variables. Rank biserial analysis for correlation was used to determine correlation between visual acuity and duration of gadget use. All data analyses were generated using IBM SPSS version 20.0.

\section{DEFINITION OF OPERATIVE TERMS}

Access to electronic gadget = ability to use the gadget, whether owned, rented or borrowed

Gadget = electronic devices that may include, but not exclusive of cell phones, tablets, laptops, desk computers, television

Visual acuity = sharpness of vision, measured by the ability to discern letters or numbers at a given distance according to a fixed standard

Snellen chart = a standard eye chart developed by a Dutch eye doctor, Dr. Hermann Snellen that contains 11 rows of capital letters. The first line has one big letter; there follows a series of lines of letters with increasing numbers and smaller sizes of letters.

Emmetropia $=$ normal visual acuity, expressed as 20/20 vision, one can see clearly at 20 feet objects that can normally be seen at that distance

Myopia $=$ nearsightedness, one has to be as close as 20 feet to see clearly objects that can be seen by person with normal vision at a farther distance, e.g. 20/40 vision
Hyperopia = farsightedness, one can see clearly at 20 feet objects that can be seen by person with normal vision at a closer distance, e.g. 20/15 vision

\section{RESULTS}

One hundred twenty pupils from the Tagbilaran City Central Elementary School were screened and enrolled in this study.

Table 1: Duration of Gadget Use by School-age Children

\begin{tabular}{|l|l|l|}
\hline Duration (minutes) & $\mathbf{n}$ & $\%$ \\
\hline$<30$ & 24 & 20.00 \\
\hline $31-60$ & 33 & 27.50 \\
\hline $61-90$ & 9 & 7.50 \\
\hline $91-120$ & 21 & 17.50 \\
\hline $121-150$ & 4 & 3.30 \\
\hline $151-180$ & 12 & 10.00 \\
\hline $181-210$ & 2 & 1.70 \\
\hline $211-240$ & 1 & 0.80 \\
\hline$>240$ & 14 & 11.70 \\
\hline TOTAL & 120 & 100 \\
\hline
\end{tabular}

Table 1 shows the distribution of pupils according to duration of gadget use. This shows that most pupils used a gadget for 1 to 1.5 hours. It is alarming to note however that $11.70 \%$ of these pupils used a gadget for more than 4 hours.

Table 2: Visual Acuity of School-age Children

\begin{tabular}{|l|l|l|}
\hline Visual Acuity & $\mathbf{n}$ & $\%$ \\
\hline Emmetropia & 111 & 92.5 \\
\hline Myopia & 9 & 7.5 \\
\hline Hyperopia & 0 & 0 \\
\hline TOTAL & 120 & 100 \\
\hline
\end{tabular}

Table 2 shows the distribution of visual acuity of school-age children. Majority of them had normal visual acuity, $7.5 \%$ had myopia, and none had hyperopia.

Table 3: Correlation of Duration of Gadget Use and Visual Acuity of School-age Children

\begin{tabular}{|l|l|l|l|l|}
\hline \multirow{2}{*}{$\begin{array}{l}\text { Duration of Gadget } \\
\text { Use (minutes) }\end{array}$} & \multicolumn{2}{|l|}{ Visual Acuity } & \multirow{2}{*}{ p-value } & $|\mathbf{r}|$ \\
\cline { 2 - 3 } & Emmetropia & Myopia & & \\
\hline$<30$ & 22 & 2 & & \\
\hline $31-60$ & 32 & 1 & \\
\hline $61-90$ & 9 & 0 & \multirow{2}{*}{0.589} \\
\hline $91-120$ & 18 & 3 & \\
\hline $121-150$ & 4 & 0 & \\
\hline $151-180$ & 10 & 2 & \\
\hline $181-210$ & 2 & 0 & \\
\hline $211-240$ & 0 & 1 & \\
\hline$>240$ & 14 & 0 & & \\
\hline
\end{tabular}


Correlation studies showed that there is no correlation between duration of gadget use and visual acuity of school-age children $(p=0.589,|r|=0.050)$. This indicates that the duration of gadget use has no impact on the development of visual acuity abnormalities in school-age children.

\section{DISCUSSION}

Gadgets have taken a niche in the everyday lives of children. These devices are used for multiple purposes from school work to recreation. The screen time varies greatly. This study shows that $27.5 \%$ of school-age children in Tagbilaran City Central Elementary School have screen time of 31 to 60 minutes per day. This is similar to that seen in South African children and adolescents who spend an average of 28.3 minutes screen time a day ${ }^{[67]}$. This result is also comparable to that seen in Japanese students. In a study by Terasaki, et al on the association of lifestyle and body structure to ocular axial length in Japanese elementary school children, it is reported that majority of the students watch television for 30 minutes to 2 hours per day, and use their computers or smart phones less than 30 minutes per day ${ }^{[68]}$.

What is also notable in the results of this study is that $11.70 \%$ of school-age children spend more than 4 hours on gadgets. This long duration of screen time is also seen in Singaporean children as reported by Toh, et al. In their study on children 10 to 18 years old, they found that the mean duration of technology use is 264 minutes per day [69]. These findings, however, are way shorter than that seen in American tweens and teens. In a nationally representative survey conducted on more than 1,600 American children aged 8 to 18 years old, it was found that children 8 to 12 years old, otherwise termed as tweens, use an average of 4 hours and 44 minutes of entertainment screen time per day, while teens 13 to 18 years old, spend an average of 7 hours and 22 minutes for entertainment screen media per day ${ }^{[70]}$.

This study shows that majority of school age children have emmetropia. This is good because a healthy eyesight is undeniably very important for the entire school experience. However, there is a small proportion (7.5\%) of children with myopia. Myopia has gained a particular importance in epidemiologic studies because of its increasing trend worldwide. It has been predicted that from 1.4 billion myopic people in 2000 , there will be 4.8 billion myopic people in 2050 [71]. The prevalence of myopia varies according to geographical location. In Delhi, India, myopia is seen in $13.1 \%$ of school children ${ }^{72}$. In the Qassim Province of Saudi Arabia, the prevalence of myopia is lower at $5.8 \%$ [73]. South American countries like Brazil, Paraguay, and Colombia have low prevalences of myopia in school children, with rates of $9.6 \%, 1.4 \%$, and $11.2 \%$ respectively ${ }^{[74-76]}$. Asians have the highest prevalence rates of myopia. In a study in South Korean children aged 7 to 11 years, myopia is seen in $58.4 \%{ }^{[77]}$. The rate is even higher in Beijing, China with prevalence as high as $70.9 \%{ }^{[78]}$. However, Philippine studies have reported a much lower prevalence rates compared to our neighboring countries. In a study conducted by Delos Reyes, et al in Luzon, myopia is reportedly seen in $3.77 \%$ of first grade students ${ }^{[79]}$. A study conducted among school children in Cebu reported that the overall prevalence of amblyopia is $5.04 \%$. These results are much lower than the prevalence of myopia seen among school-age children included in our study.

There is no case of hyperopia seen in our study. This is a contrast to studies that show that hyperopia is seen in schoolage children. For instance, in Bucaramanga, Colombia, hyperopes are more frequent than myopes (23.1\% vs $11.2 \%)$ [76]. Hyperopia is also more prevalent in Paraguayan children [75].
Hyperopia is also seen in $2.83 \%$ of first grade pupils in San Perfecto Elementary School in Greater Manila Area [79]. These differences may be explained by ethnicity and age. Ethnicity has been found to be a factor affecting the prevalence of hyperopia in children. Hyperopia is reported to be highly prevalent in Native Americans, African Americans, and Pacific Islanders [80, 81]. Hyperopia is also age-related. It is more prevalent in infants and young children until the age of 5 years, after which it tends to decrease in prevalence [82, 83]. This is probably why the study of Delos Reyes, et al found a proportion of hyperopic children since their subject population consisted exclusively of first grade students. Correlation studies show that there is no correlation between the length of gadget use and visual defect. This result differs from the results of several studies that showed that there is a higher prevalence of myopia in children 5 to 16 years. In the study by Saxena, et al, playing with computer, mobile, or video games was seen to have a positive association with myopia in urban school children in Delhi ${ }^{[72]}$. Computer use was also associated with myopia in school children in Yunnan, China ${ }^{[84]}$. A recent study among Chinese children also showed that prolonged computer and smart phone usage was significantly associated with myopic refractive error ${ }^{[85]}$.

In contrast, there are also several studies which results are similar to the results of our study. Chua, et al, investigated the association of risk factors, which included near work activity, with early-onset myopia in Singaporean preschool children. The near work activities included playing with handheld devices and using computers among others. They found in their study that neither near work nor outdoor activity was associated with myopia, and that genetic factors may rather contribute more to development of refractive errors than environmental factors ${ }^{[86]}$. In addition, a systematic review on the association between digital screen time and myopia was conducted by Lanca and Saw on 2019. They were able to include 15 studies with a total population of 49,789 children. Eleven studies investigated the relationship between screen time and prevalent or incident myopia, and 4 studies investigated the relationship between screen time and myopia progression. Of the studies that investigated the relationship between screen time and prevalent myopia, 6 studies showed that computer use is significantly associated with myopia in children aged 5 to 16 years; the remaining 5 studies did not show consistent results. Of the four studies that investigated the association between screen time and progression of myopia, only one study reported a positive association between computer/video use of $>4$ hours a week and progression of myopia. Hence, studies on screen time and myopia have mixed results. They concluded that there is no clear association between myopia and screen time ${ }^{[87]}$.

\section{CONCLUSION}

There is no correlation between duration of gadget use and visual acuity of school-age children. The duration of gadget use has no impact on the development of visual defects in schoolage children.

\section{RECOMMENDATIONS}

The authors acknowledge the fact that the results of all available studies on gadget use and visual acuity are mixed. Moreover, there is an anticipated increase in screen time by school children in this time of pandemic and virtual or e-learning; hence, further studies that use objective screen time measurements like the use of applications may be warranted. 
REFERENCES

1. Blakely M. The importance of sight and vision, 2015. Retrieved from https://www.marveloptics.com/blog/the-importance-of-sight-andvision-molly-blakely/.

2. Smart Vision Optometry. The difference between sight and vision, 2015. Retrieved from https://www.smartvisionoptometry. com.au/eyecare/eyesight-vs-vision/.

3. Chiu S-C, Chen S-W, Chiang C-K, Chung Y-C, Chang S-F. The analysis and assessment of dangerous factors in the visual lifestyle of children from the perspective of myopia prevention. Int J Nursing, 2016; 3(1):46-54

4. World Health Organization (WHO). Blindness and vision impairment, 2018. Retrieved from https://www.who.int/en/newsroom/fact-sheets/detail/blindness-and-visual-impairment.

5. Jalis M, Ashfaq MW, Imdad A. Use of Bruckner Test for the detection of significant refractive errors in children. JRMC, 2015; 19:200-203.

6. Williams KM, Verhoeven VJ, Cumberland P, Bertelsen G, Wolfram C, Buitendijk GH, Hammond CJ. Prevalence of refractive error in Europe: the European Eye Epidemiology $(E(3))$ consortium. Eur J Epidemiol, 2015; 30(4):305-315.

7. Foster PJ, Jiang Y. Epidemiology of myopia. Eye, 2014; 28(2):202208.

8. Angle J, Wissmann DA. The epidemiology of myopia. Am $J$ Epidemiol, 1980; 111(2):220-228.

9. National Eye Institute. Facts about hyperopia, 2016. Retrieved from https://nei.nih.gov/health/errors/hyperopia.

10. Boyd K. What is astigmatism? 2018. Retrieved from https://www.aao.org/eye-health/diseases/what-is-astigmatism.

11. Baltussen R, Naus J, Limburg H. Cost-effectiveness of screening and correcting refractive errors in school children in Africa, Asia, America and Europe. Health Policy, 2009; 89:201-215.

12. Maul E, Barroso S, Munoz SR, Sperduto RD, Ellwein LB. Refractive error study in children: results from La Florida, Chile. $A m$ Ophthalmol, 2000; 129(4):445-454.

13. Negrel AD, Maul E, Pokharel GP, Zhao J, Ellwein LB. Refractive error study in children: sampling and measurement methods for a multi-country survey. Am J Ophthalmol, 2000; 129(4):421-426.

14. Pokharel GP, Negrel AD, Munoz SR, Ellwein LB. Refractive error study in children: results from Mechi Zone, Nepal. Am J Ophthalmol, 2000; 129(4):436-444.

15. Zhao J, Pan X, Sui R, Munoz SR, Sperduto RD, Ellwein LB. Refractive error study in children: results from Shunyi District, China. Am J Ophthalmol, 2000; 129(4):427-435.

16. Dandona R, Dandona L, Srinivas M, Sahare $P$, Narsaiah S, Munoz SR, Ellwein LB. Refractive error in children in a rural population in India. Invest Ophthalmol Vis Sci, 2002; 43(3):615-622.

17. Murthy GVS, Gupta SK, Ellwein LB, Munoz SR, Pokharel GP, Sanga L, Bachani D. Refractive error in children in an urban population in New Delhi. Invest Ophthalmos Vis Sci, 2002; 43(3):623-631.

18. Naidoo KS, Raghunandan A, Mashige KP, Govender P, Holden BA, Pokharel GP, Ellwein LB. Refractive error and visual impairment in African children in South Africa. Invest Ophthal Vis Sci, 2003; 44(9):3764-3770.

19. He M, Zeng J, Liu Y, Xu J, Pokharel GP, Ellwein LB. Refractive error and visual impairment in urban children in Southern China. Invest Ophthal Vis Sci, 2004; 45(3):793-799.

20. Goh PP, Abqariyah Y, Pokharel GP, Ellwein LB. Refractive error and visual impairment in school-age children in Gombak District, Malaysia. Ophthalmology, 2005; 112(4):678-685.

21. He M, Huang W, Zheng Y, Huang L, Ellwein LB. Refractive error and visual impairment in school children in rural Southern China. Ophthalmology, 2007; 114(2):374-382.

22. Resnikoff S, Pascolini D, Mariotti SP, Pokharel GP. Global magnitude of visual impairment caused by uncorrected refractive errors in 2004. Bull World Health Organ, 2008; 86(1):63-70.

23. Delos Reyes G, Detran JEB, Devela MIC, Devoma KCN, Dial MED, Diaz JCE, Cruz FCS. Project Hawkeye: a cross-sectional study on the prevalence of undetected refractive errors in school-age children. The Health Sciences J, 2017; 6(2):69-75.

24. Cabello K. Eye problems in Filipino children, 2016. Retrieved from https://www.philstar.com/the-freeman/cebulifestyle/2016/10/10/1632169/eye-problems-filipino-children.

25. Hashemi H, Rezvan F, Beiranvand A, Papi OA, Hoseini Yazdi H, Ostadimoghaddam $\mathrm{H}$, Khabazkhoob $\mathrm{M}$. Prevalence of refractive errors among high school students in Western Iran. J Ophthalmic
Vis Res, 2014; 9(2):232-239.

26. Prabha V, Meriton SA. A cross sectional study on refractive error among school children aged 6 to 17 years in Chennai, India. Int $J$ Community Med Public Health, 2016; 3(1):71-73.

27. Taylor HR. Refractive errors: magnitude of the need. Community Eye Health, 2000; 13(33):1-2.

28. Dulani N, Dulani H. Prevalence of refractive errors among school children in Jaipur, Rajasthan. Int J Sci Stud, 2014; 2:52-55.

29. Cueto S, Escobal J, León J, Penny ME. Does visual acuity have an effect on children's educational achievement? 2017, Retrieved from https://www.younglives.org.uk/content/does-visual-acuityhave-effect-children's-educational-achievement.

30. Shrestha RK, Joshi MR, Ghising R, Pradhan P, Shakya S, Rizyal, A. Ocular morbidity among children studying in private schools of Kathmandu valley: a prospective cross sectional study. Nepal Med Coll J, 2006; 8:43-46.

31. You QS, Wu LJ, Duan JL, Luo YX, Liu LJ, Li X, Guo XH. Factors associated with myopia in school children in China: the Beijing childhood eye study. PLoS One, 2012; 7(12):e52668.

32. French AN, Morgan IG, Mitchell P, Rose KA. Patterns of myopigenic activities with age, gender and ethnicity in Sydney school children. Ophthalmic Physiol Opt, 2013; 33(3):318-328.

33. Peng HY. A study on myopia of preschool children and its related factors in Taiwan (Doctoral dissertation), 2011. Retrieved from http://ndltd.ncl.edu.tw/cgi-

bin/gs32/gsweb.cgi?o=dnclcdr\&s=id\%3D\%22099NTNU5571030 $\% 22 . \&$ searchmode=basic

34. French AN, Morgan IG, Mitchell P, Rose KA. Risk factors for incident myopia in Australian school children: The Sydney Adolescent Vascular and Eye Study. Ophthalmology, 2013; 120(10):2100-2108

35. Ip JM, Rose KA, Morgan IG, Burlutsky G, Mitchell P. Myopia and the urban environment: findings in a sample of 12-year old Australian school children. Investigative Ophthalmology \& Visual Science, 2008; 49(9):3858-3863.

36. Guggenheim JA, Pong-Wong R, Haley CS, Gazzard G, Saw SM. Corrections in refractive errors between siblings in the Singapore Cohort Study of Risk factors for Myopia. Br J Ophthalmol, 2007; 91(6):781-784

37. Williams KM, Hammond CJ. Prevalence of myopia and association with education in Europe. The Lancet, 2014; 383, S109.

38. Chiu SC, Chen SW, Chiang CK, Chung YC, Chang SF. The analysis and assessment of dangerous factors in the visual lifestyle of children from the perspective of myopia prevention. Int $J$ Nursing, 2016; 3(1):46-54.

39. Ong E, Ciuffreda KJ. Nearwork-induced transient myopia: a critical review. Doc Ophthalmol, 1995; 91(1):57-85.

40. Ciuffreda KJ, Vasudevan B. Nearwork-induced transient myopia (NITM) and permanent myopia - is there a link? Ophthalmic Physiol Opt, 2008; 28(2):103-114.

41. Rah MJ, Walline JJ, Mitchell GL, Zadnik K. Comparison of the experience sampling method and questionnaires to assess visual activities in pre-teen and adolescent children. Ophthalmic \& Physiological Optics, 2006; 26(5):483-489.

42. Guo Y, Liu L, Xu L, Tang P, Lv YY, Feng Y, Jonas JB. Myopic shift and outdoor activity among primary school children: one-year follow-up study in Beijing. PLoS One, 2013; 8(9):e75260.

43. Guggenheim JA, Northstone K, McMahon G, Ness AR, Deere K, Mattocks C, Williams C. Time outdoors and physical activity as predictors of incident myopia in childhood: a prospective cohort study. Invest Ophthalmol Vis Sci, 2012; 53(6):2856-2865.

44. Guo Y, Liu L, Xu L, Lu Y, Tang P, Feng Y. Outdoor activity and myopia among 681 primary students in urban and rural regions of Beijing. Zhonghua Yi Xue Za Zhi, 2014; 94(3):191-194.

45. Sundus M. The impact of using gadgets on children. J Depress Anxiety, 2018; 7:296.

46. Life Being Momma. Effects of gadgets on baby's development, $2018 . \quad$ Retrieved from https://lifebeingmomma.com/2018/04/16/effects-of-gadgets-onbabys-development/.

47. Nair A. Parents, beware - this is how gadgets are harming your little child, $2018 . \quad$ Retrieved from https://parenting.firstcry.com/articles/parents-beware-this-is-howgadgets-are-harming-your-little-child/.

48. Centers for Disease Control and Prevention (CDC). Screen time vs lean time infographic, 2017. Retrieved from https://www.cdc.gov/nccdphp/dch/multimedia/infographics/getmov 
ing.htm.

49. Yen HK. Blurry future for kids on gadgets, doctor warns, 2015. Retrieved https://www.malaymail.com/news/malaysia/2015/01/31/blurryfuture-for-kids-on-gadgets-doctor-warns/831177.

50. Mathew P. Excessive screen time strains children's eyes, 2017. Retrieved from https://gulfnews.com/lifestyle/excessive-screentime-strains-childrens-eyes-1.2098960.

51. Deccan Chronicle. Mobile phone, tv trigger vision impairment, says experts, 2018 from https://www.deccanchronicle.com/lifestyle/health-andwellbeing/270318/mobile-phone-tv-trigger-vision-impairment-sayexperts.html.

52. Crisostomo S. 'Epidemic' of nearsightedness among children alarms DOH, 2018. Retrieved from https://www.philstar.com/headlines/2018/08/14/1842411/epidemic -nearsightedness-among-children-alarms-doh.

53. Heiting G. Children and technology: protecting your child's eyes, 2018 Retrieved from https://www.allaboutvision.com/parents/children-computer-visionsyndrome.htm.

54. Ranasinghe $P$, Wathurapatha WS, Perera YS, Lamabadusuriya DA, Kulatunga S, Jayawardana N, Katulanda P. Computer vision syndrome among computer office workers in a developing country: an evaluation of prevalence and risk factors. BMC Res Notes, 2016; 9:150.

55. Parihar JK, Jain VK, Chaturvedi P, Kaushik J, Jain G, Parihar AK. Computer and visual display terminals (VDT) vision syndrome (CVDTS). Med J Armed Forces India, 2016; 72(3):270-276.

56. Child Development Institute. How gadgets and digital screens are harming your child, 2017. Retrieved from https://childdevelopmentinfo.com/child-health-news/how-gadgetsand-digital-screens-are-harming-your-child/\#.XJJTNC17E4Y.

57. Wu H, Wang Y, Dong N, Yang F, Lin Z, Shang X, Li C. Meibomian gland dysfunction determines the severity of the dry eye conditions in visual display terminal workers. PLoS One, 2014; 9(8):e105575.

58. Bhootra AK. Computer vision syndrome. In (Eds.), Basics of computer vision syndrome (pp. 11-18). New Delhi, India: Jaypee Brothers Medical Publishers, 2014.

59. Blehm C, Vishnu S, Khattak A, Mitra S, Yee RW. Computer vision syndrome: a review. Surv Ophthalmol, 2005; 50(3):253-262.

60. Bogdānici CM, Sāndulache DE, Nechita CA. Eyesight quality and computer vision syndrome. Romanian J Ophthalmol, 2017; 61(2):112-116

61. Chellavel Ganapathi K, Arun Vijay Paul R, Kokila K, Kumar BS. A study on prevalence of myopia and its associated factors in school children in Salem, Tamil Nadu. Int J Community Med Public Health, 2017; 4(8):2741-2744

62. Kitchel E. (n. d.). The effects of blue light on ocular health. Retrieved from https://www.tsbvi.edu/instructional-resources/62 family-engagement/3654-effects-of-blue-light.

63. Ham WT, Jr. Ruffolo JJ, Jr. Mueller HA, Guerry DIII. The nature of retinal radiation damage: dependence on wavelength, power level and exposure time; the quantitative dimensions of intense light damage as obtained from animal studies, Section II. Applied Research, 1980; 20:1005-1111.

64. Pautler EL, Morita M, Beezley D. Reversible and irreversible blue light damage to the isolated, mammalian pigment epithelium. Proceedings of the International Symposium on Retinal Degeneration (pp. 555-567). New York, USA: Liss, 1989.

65. Chen E. Inhibition of cytochrome oxidase and blue-light damage in rat retina. Graefes Arch Clin Exp Ophthalmol, 1993; 231(7):416 423.

66. Department of Health (DOH). Prevention of blindness program, 2004. Retrieved from https://www.doh.gov.ph/national-preventionof-blindness-program.

67. Chetty-Mhlanga S, Fuhrimann S, Eeftens M, Basera W, Hartinger S, Dalvie MA, Röösli M. Different aspects of electronic media use, symptoms and neurocognitive outcomes of children and adolescents in the rural western cape region of South Africa. Environ Res, 2020; 184, 109315. doi: 10.1016/j.envres.2020.109315

68. Terasaki H, Yamashita T, Yoshihara N, Kii Y, Sakamoto T. Association of lifestyle and body structure to ocular axial length in Japanese elementary school children. BMC Ophthalmol, 2017 17:123. doi: 10.1186/212886-017-0519-y.

69. Toh SH, Coenen P, Howie EK, Mukherjee S, Mackey DA, Straker
LM. Mobile touch screen device use and associations with musculoskeletal symptoms and visual health in a nationally representative sample of Singaporean adolescents. Ergonomics, 2019; 62(6):778-793.

70. Rideout V, Robb MB. The Common Sense census: media use by tweens and teens, 2019 (p. 3). San Franciso, CA: Common Sense Media, 2019.

71. Holden BA, Fricke TR, Wilson DA, Jong M, Naidoo KS, Sankaridurg $\mathrm{P}$, Resnikoff S. Global prevalence of myopia and high myopia and temporal trends from 2000 through 2050. Ophthalmology, 2016; 123(5):1036-1042. doi: 10.1016/j.ophtha.2016.01.006.

72. Saxena R, Vashist P, Tandon R, Pandey RM, Bhardawai A, Menon $\mathrm{V}$, Mani K. Prevalence of myopia and its risk factors in urban school children in Delhi: the North India Myopia Study (NIM Study). PLoS One, 2015; 10(2), e0117349. doi: 10.1371/journal.pone.0117349.

73. Aldebasi $\mathrm{YH}$. Prevalence of correctable visual impairment in primary school children in Qassim Province, Saudi Arabia. Optom, 2014; 7(3):168-176. doi: 10.1016/j.optom.2014.02.001.

74. Lira RP, Arieta CE, Passos TH, Maziero D, Valle Astur GL, Espirito Santo IF, Ferraz AA. Distribution of ocular component measures and refraction in Brazilian school children. Ophthalmic Epidemiol, 2017; 24(1):29-35.

75. Carter MJ, Lansingh VC, Schacht G, del Amo MR, Scalamogna M, France TD. Visual acuity and refraction by age for children of three different ethnic groups in Paraguay. Arq Bras Oftalmol, 2013; 76(2):94-97. doi: 10.1590/s0004-27492013000200008.

76. Galvis V, Tello A, Otero J, Serrano AA, Gomez LM, Castellanos Y. Refractive errors in children and adolescents in Bucaramanga (Colombia). Arq Bras Oftalmol, 2017; 80(6):359-363. doi: 10.5935/0004-2749.20170088

77. Rim TH, Kim SH, Lim KH, Choi M, Kim HY, Baek SH. Refractive errors in Koreans: the Korea National Health and Nutrition Examination Survey 2008-2012. Korean J Ophthalmol, 2016; 30(3):214-224. doi: 10.3341/kjo.2016.30.3.214.

78. Guo Y, Duan JL, Liu LJ, Sun Y, Tang P, Lv YY, Jonas JB. High myopia in Greater Beijing school children in 2016. PLoS One, 2017; 12(11), e0187396. doi: 10.1371/journal.pone.0187396.

79. Delos Reyes G, Detran JB, Devela MC, Devoma KN, Dial MD, Diaz JE, Cruz FS. Project Hawkeye: a cross-sectional study on the prevalence of undetected refractive errors in school-age children. The Health Sciences Journal, 2017; 6(2):69-75.

80. Post RH. Population differences in vision acuity: a review, with speculative notes on selection relaxation. Biodemography and Social Biology, 1982; 29(3-4):319-343. doi: 10.1080/19485565.1962.9987526

81. Crawford HE, Hamman GC. Racial analysis of ocular defects in the schools of Hawaii. Hawaii Med J, 1949; 9(2):90-93.

82. Van Alphen G. On emmetropia and ametropia. Opt Acta (Lond), 1961; 142(Suppl):1-92.

83. Mohindra I, Held R. Refraction in humans from birth to five years. Doc Ophthalmol Proc Ser, 1981; 28:19-27.

84. Qian DJ, Zhong H, Li J, Niu Z, Yuan Y, Pan CW. Myopia among school students in rural China (Yunnan). Ophthalmic Physiol Opt, 2016; 36(4):381-387. doi: 10.1111/opo12287.

85. Guan H, Yu NN, Wang H, Boswell M, Shi Y, Rozelle S, Congdon $\mathrm{N}$. Impact of various types of near work and time spent outdoors at different times of day on visual acuity and refractive error among Chinese school-going children. PLoS One, 2019; 14(4):e0215827.

86. Chua SY, Ikram MK, Tan CS, Lee YS, Ni Y, Shirong C, Saw SM. Relative contribution of risk factors for early-onset myopia in young Asian children. Invest. Ophthalmol. Vis. Sci. 2015; 56(13):81018107. doi: 10.1167/iovs.15-16577.

87. Lanca C, Saw SM. The association between digital screen time and myopia: a systematic review. Ophthalmic Physiol Opt, 2020; 40:216-229. 